\title{
Article/Artigo
}

\section{Validation of a case definition for leptospirosis diagnosis in patients with acute severe febrile disease admitted in reference hospitals at the State of Pernambuco, Brazil}

\author{
Validação de uma definição de caso para diagnóstico de leptospirose em pacientes com doença febril \\ aguda grave, admitidos em hospitais de referência do Estado de Pernambuco, Brasil
}

\begin{abstract}
Alfredo Pereira Leite de Albuquerque Filho ${ }^{1}$, Jéssica Guido de Araújo ${ }^{1}$, Inacelli Queiroz de Souza ${ }^{1}$, Luciana Cardoso Martins ${ }^{2}$, Marta Iglis de Oliveira ${ }^{2}$, Maria Jesuíta Bezerra da Silva ${ }^{3}$, Ulisses Ramos Montarroyos ${ }^{4}$ and Demócrito de Barros Miranda Filho ${ }^{2,5}$
\end{abstract}

\begin{abstract}
Introduction: Leptospirosis is often mistaken for other acute febrile illnesses because of its nonspecific presentation. Bacteriologic, serologic, and molecular methods have several limitations for early diagnosis: technical complexity, low availability, low sensitivity in early disease, or high cost. This study aimed to validate a case definition, based on simple clinical and laboratory tests, that is intended for bedside diagnosis of leptospirosis among hospitalized patients. Methods: Adult patients, admitted to two reference hospitals in Recife, Brazil, with a febrile illness of less than 21 days and with a clinical suspicion of leptospirosis, were included to test a case definition comprising ten clinical and laboratory criteria. Leptospirosis was confirmed or excluded by a composite reference standard (microscopic agglutination test, ELISA, and blood culture). Test properties were determined for each cutoff number of the criteria from the case definition. Results: Ninety seven patients were included; 75 had confirmed leptospirosis and 22 did not. Mean number of criteria from the case definition that were fulfilled was $7.8 \pm 1.2$ for confirmed leptospirosis and $5.9 \pm 1.5$ for non-leptospirosis patients $(p<0.0001)$. Best sensitivity $(85.3 \%)$ and specificity $(68.2 \%)$ combination was found with a cutoff of 7 or more criteria, reaching positive and negative predictive values of $90.1 \%$ and $57.7 \%$, respectively; accuracy was $81.4 \%$. Conclusions: The case definition, for a cutoff of at least 7 criteria, reached average sensitivity and specificity, but with a high positive predictive value. Its simplicity and low cost make it useful for rapid bedside leptospirosis diagnosis in Brazilian hospitalized patients with acute severe febrile disease.
\end{abstract}

Keywords: Leptospirosis. Case definition. Clinical diagnosis. Validation study.

\section{RESUMO}

Introdução: Por sua apresentação clínica inespecífica, a leptospirose é frequentemente confundida com outras doenças febris agudas. Métodos bacteriológicos, sorológicos e moleculares apresentam limitações para o diagnóstico precoce: complexidade técnica, baixa disponibilidade, insensibilidade na doença precoce, ou alto custo. Este estudo objetivou validar uma definição de caso, baseada em dados clínicos e laboratoriais simples, destinada ao diagnóstico da leptospirose em pacientes hospitalizados. Métodos: Foram incluídos pacientes adultos, admitidos em 2 hospitais de referência no Recife, com doença febril de até 21 dias e suspeita clínica de leptospirose, para testar uma definição de caso contendo 10 critérios clínico-laboratoriais. Leptospirose foi confirmada ou afastada por uma combinação de teste de aglutinação microscópica, ELISA e hemoculturas. Foram determinadas as propriedades do teste, para cada número de critérios da definição de caso preenchidos. Resultados: Incluíram-se 97 pacientes, 75 com leptospirose e 22 negativos para a doença. O número médio de critérios da definição de caso preenchidos foi $7,8 \pm 1,2$ e 5,9 91,5 , respectivamente ( $p<0,0001$ ). A melhor combinação de sensibilidade $(85,3 \%)$ e especificifidade $(68,2 \%)$ foi obtida com a presença de 7 ou mais critérios, atingindo valores preditivos positivo de $90,1 \%$ e negativo de $57,7 \%$, e acurácia $81,4 \%$. Conclusões: A definição de caso proposta, com um ponto de corte de pelo menos 7 critérios presentes, alcançou sensibilidade e especificidade moderadas, mas um elevado valor preditivo positivo. Sua simplicidade e o baixo custo tornam-na útil para o diagnóstico rápido da leptospirose à beira do leito, em pacientes brasileiros hospitalizados com doença aguda febril grave.

Palavras-chaves: Leptospirose. Definição de caso. Diagnóstico clínico. Estudo de validação.

1. Enfermaria de Clínica Médica, Hospital Barão de Lucena, Recife, PE. 2. Serviço de Doenças Infecciosas e Parasitárias, Hospital Universitário Oswaldo Cruz, Recife, PE. 3. Setor de Bacteriologia, Laboratório Central de Saúde Pública Dr. Milton Bezerra Sobral, Recife, PE. 4. Programa de Pós Graduação em Medicina Tropical, Universidade Federal de Pernambuco, Recife, PE. 5. Departamento de Medicina Clínica, Universidade de Pernambuco, Recife, PE.

Address to: Dr. Alfredo Pereira Leite de Albuquerque Filho. Enfermaria de Clínica Médica/Hospital Barão de Lucena. Avenida Caxangá 3860, 50731-000 Recife, PE, Brasil.

Phone: 5581 3184-6606

e-mail: alfredoleite72@gmail.com

Received in 16/06/2010

Accepted in 28/07/2011

\section{INTRODUCTION}

Leptospirosis is an endemic disease that occurs mainly in tropical regions. It is associated with high morbidity and still causes many deaths, predominantly among previously health young people. As the symptoms and signs of leptospirosis are commonly found in other acute febrile illnesses, it is often mistaken for other infectious (dengue, viral hepatitis, pneumonia, cholangitis, and others) and noninfectious diseases ${ }^{1}$. To initiate appropriate therapeutical measures, such as antibiotics and directed supportive care, it is important to diagnose leptospirosis as soon as possible after hospital admission. Specific diagnostic tools for the disease include blood cultures for leptospiras, serologic methods [microscopic agglutination test (MAT) and enzyme-linked immunosorbent assay (ELISA)], as well as molecular methods [such as polymerase chain reaction (PCR)]. However, all these methods have serious limitations for early and immediate diagnosis. For instance, blood cultures are timeconsuming, technically demanding, and have very low sensitivity. Serological methods and PCR are also insensitive during the first week of symptoms, when many patients come to the hospital; MAT is technically complex. All of these methods are expensive and available only at reference laboratories, especially in developing countries such as Brazil. It is estimated that, in this country, diagnosis is confirmed in no more than $25 \%$ of the cases ${ }^{2}$. Therefore, there is still a demand for an accurate, quickly available, and cheap diagnostic test for leptospirosis.

Although the clinical picture of the disease is considered nonspecific, some authors have tried to validate clinical criteria for diagnosis ${ }^{3-6}$. Three of these studies validated Faine's criteria, obtaining varying sensitivities ( $41.9 \%$ to $88.9 \%$ ), specificities ( $72.9 \%$ to $84.9 \%)$, positive predictive values (30.8\% to $41.9 \%)$, and negative predictive values 
( $84.9 \%$ to $98.6 \%)^{3-5}$. The low positive predictive values put in doubt the utility of these criteria to assist in decisions taken at the bedside. Other authors validated Sri Lanka's Ministry of Health criteria (slightly modified from the World Health Organization (WHO) criteria), obtaining a better positive predictive value $(78 \%)^{6}$. None of these criteria have been validated for use in the epidemiologic context of a Brazilian hospital.

The main objective of the present study is to validate a case definition, based on simple clinical data and routine laboratory tests, which can be applied for bedside diagnosis of leptospirosis in reference hospitals of an endemic region in Brazil.

\section{METHODS}

Patients were consecutively admitted to two reference hospitals [Hospital Barão de Lucena (HBL) and Hospital Universitário Oswaldo Cruz (HUOC)] in Recife, a great city in Northeastern Brazil. They were recruited from February to December 2009, irrespective of the rainy season (that occurs from March to September). Informed consent was obtained from all participants or from their relatives, when patients were unconscious or were aged younger than 18 years. Subjects of either sex, aged 15 years or older, were included if they had a history of fever with a duration of 21 days or less and had leptospirosis as one of the diagnostic possibilities listed by the admitting physician.

Exclusion criteria were the inability to provide clinical information at hospital admission, as well as the awareness of a confirmed diagnosis for the febrile disease before hospital entry. Patients were considered study losses if they (or their relatives, when appropriate) refused to participate in the study; if data pertaining to either the clinical or laboratorial items that comprised the case definition were unavailable; or if there were missing laboratory data that prevented confirmation or exclusion of leptospirosis diagnosis, including cases in which there was discordance between ELISA (positive) and MAT (negative) test results.

All patients had clinical data, and a single blood sample was collected at admission. The presence of headache, generalized myalgias, myalgias that predominated in calf muscles, suspicious environmental exposure, conjunctival suffusion, hemoptysis, and jaundice was evaluated; serum bilirubin, urea, creatinine, and potassium concentrations as well as total and differential leukocyte count were tested. All patients admitted up to the seventh day of symptoms had samples for blood cultures for leptospiras collected, unless they had already taken antimicrobials. Cultures were performed in Ellinghausen-McCullough-Johnson-Harris (EMJH) media. After the seventh day of symptoms, patients had blood samples collected for ELISA-IgM and first MAT testing. Second samples were collected for convalescent MAT testing two weeks or more after the first sample. ELISA tests were performed at Laboratório Central de Saúde Pública Dr. Milton Bezerra Sobral (LACEN), the local reference laboratory in Recife. MAT tests included antigens for the search of 22 serovars and were performed in the national reference laboratory of the Fundação Oswaldo Cruz, in the City of Rio de Janeiro.

Patients were considered as having confirmed leptospirosis (cases) if they fulfilled at least one of the following criteria: a positive blood culture; a positive ELISA test; a positive MAT with title equal or above 1:800; or the demonstration of a negative (or a lower than 1:800 titer) MAT that became positive (or increased at least four times) after a minimal 2-week interval, respectively.

Patients were considered without leptospirosis (non-cases) if they fulfilled all the following conditions: negative blood culture, when it had been done; negative ELISA, with sample collected at least 7 days after the beginning of symptoms; negative results for the two paired samples of the MAT; or low titer (less than 1:800) first sample positive MAT that did not increase at least four times in the paired sample.

The case definition designed for this study comprised ten criteria, all of them equally valued (Table 1 ).

Data were stored in a database (Microsoft Access) using double entry to check for discordant typing. All statistical analyses were performed using a statistical software package (Epi Info 2000). Cases and non-cases were compared with respect to age, gender, and duration of symptoms before hospital admission. To verify differences involving parametric variables, the analysis of variance (ANOVA) test was utilized. To determine the association between qualitative variables, the Pearson's Chi-square test was performed. Tests were interpreted under a significance level of 5\%. As it was the first time in which this case definition was tested, we did not predetermine a cutoff number of the present criteria for positivity. For each cutoff number of the criteria, from 0 to 10 , we calculated the sensitivity, the specificity, the positive predictive value and the negative predictive value with respective $95 \%$ confidence intervals, and the accuracy of the case definition. A receiver operating characteristic (ROC) curve was constructed to determine the best cutoff number of the criteria, based on the best sensitivity and

TABLE 1 - Case definition to be validated in the present study.

\begin{tabular}{l}
\hline Patient aged $\mathbf{1 5}$ years or older, with fever of less than $\mathbf{2 1}$ days duration, presenting any of the clinical or laboratory data below \\
\hline headache \\
\hline myalgias \\
\hline myalgias that predominate in calf muscles \\
\hline suspicious environmental exposure* \\
\hline conjunctival suffusion \\
\hline hemoptysis \\
\hline jaundice or hyperbilirubinemia (serum direct bilirubin $1.8 \mathrm{mg} / \mathrm{dl}$ or higher) \\
\hline absence of leucopenia (total leucocyte count 5,000 cells $/ \mathrm{mm}^{3}$ or higher) \\
\hline azotemia (either serum urea concentration higher than $40 \mathrm{mg} / \mathrm{dl}$ or serum creatinine concentration higher than $1.2 \mathrm{mg} / \mathrm{dl})$ \\
\hline absence of hyperkalemia (total serum potassium of $5.0 \mathrm{mEq} / 1$ or lower) \\
\hline${ }^{*}$ Exposure to floods, mud, or potentially contaminated water collections; exposure to septic drains or pits; occupational risky activities \\
such as rubbish handling, unblocking of water streams, animal handling or farming in flooded areas.
\end{tabular}


specificity combination of the test; the area under the ROC curve was calculated. In addition, we calculated the likelihood ratios for each cutoff number of the criteria.

\section{Ethical considerations}

The study protocol is in accordance with the revised Declaration of Helsinki and was approved by the local ethics research committee (Comitê de Ética em Pesquisa em Seres Humanos do Complexo Hospitalar HUOC/PROCAPE), under number 139/2008.

\section{RESULTS}

From February to December 2009, 120 patients were recruited -64 from HBL and 56 from HUOC. Of them, 5 were lost because they had missing information on one of the laboratorial criteria from the case definition. No patients had missing clinical criteria.

Another 18 patients were also considered study losses: 14 patients did not have convalescent serum MAT samples collected (4 died before the seventh day after the beginning of symptoms, and 10 did not attend follow-up visits), whereas 4 patients had discordant results from confirmatory tests (positive ELISA but negative convalescent phase MAT results). Therefore, the final analysis included the remaining 97 patients: 75 had a diagnosis of leptospirosis as confirmed by the gold standard (cases), and 22 had that diagnosis denied (non-cases). For the 75 cases, diagnosis was confirmed by a combination of positive MAT, ELISA, and blood culture in 2 (2.7\%) subjects; by both MAT and ELISA in 51 (68\%) subjects; by MAT alone in 3 (4\%) subjects; and by ELISA alone in 19 (25.3\%) subjects. Serovars most often identified by MAT were L copenhageni $(61.6 \%$ of patients), L. icterohaemorragiae (27.5\%), and L. tarassovi (4.5\%).

Cases were more often male (93.3\%) than non-cases (63.6\%), $p=0.002$. Cases were aged $32.3 \pm 12.7$ years old and not statistically different from non-cases $(34.8 \pm 15.0$ years old, $\mathrm{p}=1.0)$. Patients lost from the study were older $(43.6 \pm 19.3$ years, $\mathrm{p}=0.009$ when compared to cases), with a gender distribution that was intermediate between the study groups (Table 2).

From the whole group of 97 patients included, 24 were initially admitted to the intensive care unit (ICU), whereas the remaining 73 (75.3\%) patients were admitted to the wards. In groups CL and NL, $30.7 \%$ and $4.6 \%$ were admitted to the ICU, respectively $(\mathrm{p}=0.04)$.

Among the cases, $72 \%$ had leptospirosis as the single diagnosis suggested by the physician responsible for hospital admission, while this happened for only $13.6 \%$ of non-cases $(p<0.001)$. The diseases more often suggested as alternative diagnoses in the 75 cases were dengue (16 citations), viral hepatitis (13 citations), and hantavirosis ( 3 citations). In the 22 non-cases, the alternative diagnoses more often suggested were dengue (10 citations) and viral hepatitis ( 9 citations). Other diseases mentioned as alternative diagnoses are listed in Table 3.

Cases had environmental exposures suggestive of potential contact with leptospiras in $90.7 \%$ of cases; this happened to $77.3 \%$ of non-cases (non-significant difference, $\mathrm{p}=0.09$ ).

Most patients admitted before the seventh day of symptoms had received antibiotics prior to having their blood culture samples collected. Only 12 patients had blood cultures for leptospiras performed, of whom 4 were non-cases (with negative results) and 8 were samples from cases. Two of these last 8 blood cultures (25\%) showed positive results; both of these patients had also positive ELISA and MAT results.

The mean number of criteria of the case definition that were fulfilled was $7.8 \pm 1.2$ for cases and $5.9 \pm 1.5$ for non-cases, showing a statistically significant difference $(\mathrm{p}<0.0001)$.

The test properties - sensitivity, specificity, positive, and negative predictive values, with their respective confidence intervals -

TABLE 2 - Demographic data and duration of symptoms before admission from cases, non-cases, and lost patients.

\begin{tabular}{lcccc}
\hline & $\begin{array}{c}\text { Cases } \\
(\mathbf{n}=\mathbf{7 5})\end{array}$ & $\begin{array}{c}\text { Non-cases } \\
(\mathbf{n = 2 2})\end{array}$ & $\begin{array}{c}\text { Cases and non-cases } \\
(\mathbf{n}=\mathbf{9 7})\end{array}$ & $\begin{array}{c}\text { Lost patients } \\
(\mathbf{n}=\mathbf{2 3})\end{array}$ \\
\hline Age (years, $\pm \mathrm{SD})$ & $32.3(12.7)$ & $34.8(15.0)$ & $32.9(13.2)$ & $41.4(18.8)^{*}$ \\
\hline Sex, male $(\%)$ & 93.3 & $63.6^{* *}$ & 86.6 & 82.6 \\
\hline Duration of symptoms before admission (days, $\pm \mathrm{SD})$ & $6.4(2.5)$ & $5.2(2.7)$ & $6.1(2.6)$ & $5.0(2.6)$ \\
\hline $\begin{array}{l}* \mathrm{p}=0.01 \text { for difference between included (cases and non-cases) and lost patients; }{ }^{* *} \mathrm{p}=0.002 \text { for difference between cases and } \\
\text { non-cases; SD: Standard definition. }\end{array}$ & & &
\end{tabular}

TABLE 3 - Alternative diagnoses initially suggested by the admitting physician for cases and non-cases.

\begin{tabular}{lcc}
\hline Alternative hypothesis & Cases $(\mathbf{n = 7 5})$ & Non-cases $(\mathbf{n}=\mathbf{2 2})$ \\
\cline { 2 - 3 } & $\mathbf{\%}$ & 21.3 \\
\hline Dengue & 17.3 & 45.4 \\
\hline Viral hepatitis & 4.0 & 40.9 \\
\hline Hantavirosis & 1.3 & - \\
\hline Yellow fever & 2.7 & - \\
\hline Cholangitis & 1.3 & 4.5 \\
\hline Community-acquired pneumonia & - & 9.1 \\
\hline Urinary tract infection & 1.3 & - \\
\hline Cholecystitis, influenza, endocarditis & - & 4.5 \\
\hline $\begin{array}{l}\text { Leg cellulitis, biliary obstruction, alcoholic hepatitis, bacterial meningitis, } \\
\text { immune thrombocytopenic purpura, sepsis, unspecified viral syndrome }\end{array}$ & & \\
\hline
\end{tabular}


and accuracy obtained for each cutoff number of criteria (from 5 or more to 9 or more) are shown in Table 4. The remaining cutoff levels ( 0 to 4 or more, and 10 criteria) were not shown because sensitivity or specificity levels obtained were clearly unacceptable. The best sensitivity ( $85.3 \%)$ and specificity (68.2\%) combination was found when having 7 or more criteria as cutoff (Figure 1). For this cutoff level, a positive predictive value of $90.1 \%$, a negative predictive value of $57.7 \%$, and an accuracy of $81.4 \%$ were reached. The area under the curve (AUC) was 0.83 (95\% confidence interval, 0.72 to 0.94 ).

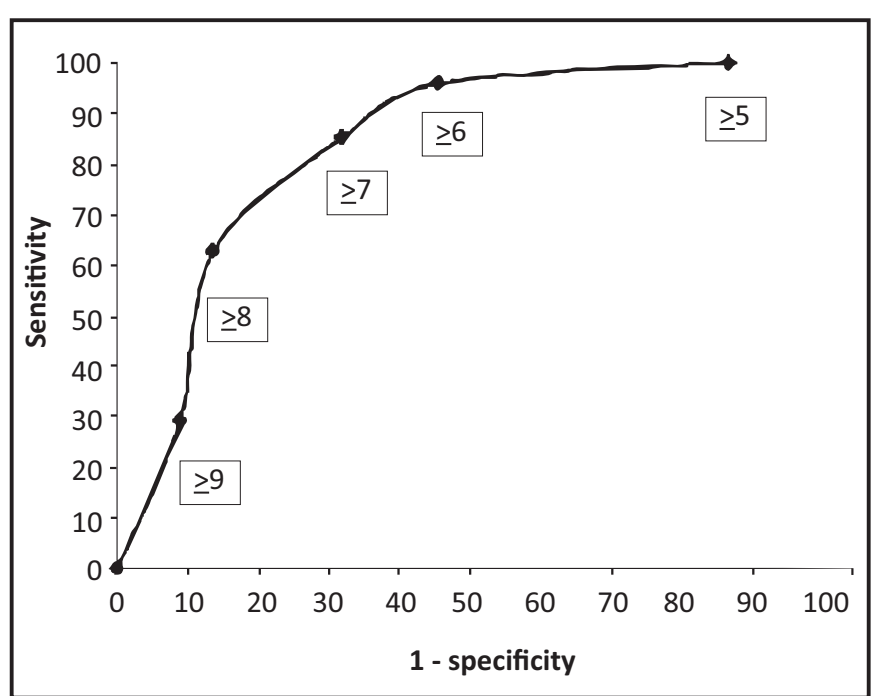

FIGURE 1 - Receiver operating characteristic curve. The number of criteria from the case definition fulfilled is shown on the boxes.

\section{DIscussion}

The present study validated a case definition of leptospirosis, based on clinical findings and simple laboratory tests, aimed for patients with acute severe febrile disease admitted to reference tertiary-care hospitals in Northeastern Brazil. The best sensitivity and specificity values were obtained for a cutoff of 7 or more criteria. Although levels of sensitivity and specificity were a little lower than those observed with other definitions, such as Faine's and the modified WHO criteria, the present study's definition attained a high positive predictive value, making it attractive for usage in the specific population evaluated. Furthermore, interpreting the likelihood ratios obtained suggests that the case definition can significantly raise the pretest probability of leptospirosis diagnosis ${ }^{7}$.

The sample studied seems to be representative of the average patients usually admitted to our reference hospitals with suspected leptospirosis: predominantly young adult male subjects. The subjects were admitted to the hospital 5 to 6 days after the beginning of symptoms, a time point in which serologic methods have low sensitivity; this reinforces the demand for a test that can make an early diagnosis of the disease. As expected, non-cases had proportionately more alternative diagnoses suggested by the admitting physicians. Dengue and viral hepatitis were, by far, the more cited ones for both cases and non-cases, although 15 more diseases were thought about. It is interesting to note that in $3(13.6 \%)$ patients who were non-cases, leptospirosis was the sole diagnosis proposed upon admission, leading probably to equivocal therapeutic decisions. The epidemiologic component of the case definition (exposure to potentially contaminated environment) was present almost as often in cases as in non-cases, with a non-significant difference. It suggests that the discriminative potential of this information should not be overvalued when differentiating leptospirosis from other diseases in our epidemiologic context. This assumption would argue against the utilization of Faine's criteria in our hospitals, as that case definition attributes a heavy weight to suspicious exposure ${ }^{8}$.

Direct comparisons of the present study with previous work on the subject demand some considerations. First, one of the studies that validated Faine's criteria included outpatients as well as inpatients ${ }^{3}$. In contrast, only hospitalized subjects were included in the present study, suggesting they had more severe disease. In fact, it should be noted that one quarter of our patients were admitted directly to the ICU. The other two studies validating Faine's criteria ${ }^{4-5}$, as well as the study validating the modified $\mathrm{WHO}$ criteria ${ }^{6}$, included only hospitalized patients. However, they elected to include all patients who were admitted with fever. In contrast, the present study only included subjects in whom leptospirosis was specifically suspected by the admitting physician. This restriction puts these patients in a situation of higher pretest probability of having leptospirosis, qualifying the present study as a Phase III validation study ${ }^{9}$. This category of validation studies evaluates the capability of the test in distinguishing patients with and without the disease among patients in whom it is clinically reasonable to suspect that the disease is present ${ }^{9}$. In such context, test properties can be reduced, and the test can appear less useful ${ }^{7}$. The three studies validating Faine's criteria obtained varying sensitivities ( $41.9 \%$ to $88.9 \%$ ), specificities $(72.9 \%$ to $84.9 \%)$, positive predictive values ( $30.8 \%$ to $41.9 \%)$, and negative predictive values $(84.9 \% \text { to } 98.6 \%)^{3-5}$. The study conducted in Sri Lanka, which evaluated the modified WHO criteria, showed $91.9 \%$, $73.8 \%, 78.1 \%$, and $90 \%$ for the same parameters above, respectively, with an accuracy of $82.9 \%$. The comparably high positive predictive value of the present case definition (90.1\%) makes it attractive for use at the bedside, assisting in therapeutic decisions. 
The present study fulfills the main principles for the validity of diagnostic test studies ${ }^{10}$. First, we performed an independent, blind comparison of our test (the case definition) with a reference standard. It should be emphasized that we used MAT test (usually considered the reference standard for leptospirosis diagnosis) for confirmation of $75 \%$ of cases. The remaining $25 \%$ of patients were confirmed by ELISA-IgM, a test with high sensitivity and specificity, when compared with $\mathrm{MAT}^{11-13}$. In fact, the Brazilian Health Ministry recommends the use of either ELISA or MAT for specific diagnosis of leptospirosis ${ }^{14}$. The US Food and Drug Administration has also approved the commercial utilization of ELISA ${ }^{15}$. Second, the spectrum of patients included was precisely the same in which the case definition is to be applied in practice, in particular, those with acute and severe febrile disease, admitted to reference hospitals with a clinical suspicion of having leptospirosis. Third, the reference standard was performed in all patients who fulfilled the inclusion criteria, independently of the test (case definition) results. This minimized the so-called verification bias ${ }^{16}$.

On the other hand, the present study has some limitations. First, the number of subjects was small, notably in non-cases. The stringent inclusion criteria, limiting entry to patients with a previous suspicion of leptospirosis diagnosis at hospital admission, contributed to it. However, 14 patients who had negative ELISA and first MAT samples did not have the convalescent phase serum collected, either because they died or did not attend follow-up visits. As several of these subjects had ELISA samples collected after the seventh day of symptoms (data not shown), it is reasonable to presume that many of them, notably the non-attendants, would have been non-cases. Hence, these omissions (lost cases) reduced the power of the validation parameters, enlarging its confidence intervals. Second, we did not pursue the alternative diagnoses in the patients who were assumed not to have leptospirosis. It was not pursued because of local resource limitations. However, our definition of non-leptospirosis cases was very stringent and was based on the best practice in serological diagnosis of the disease. The small number of blood cultures performed is not a real limitation, if we consider the low sensitivity of this test ${ }^{17}$.

Lastly, it should be considered that the case definition was tested in a specific epidemiologic context, namely, the state of Pernambuco, Brazil, in 2009, among hospitalized patients with acute severe febrile disease. Differences in the nosological profile at other regions, as well as an option to evaluate non-hospitalized patients, would be a demand for a new validation of the diagnostic tool.

The present study designed and validated a case definition for leptospirosis diagnosis, based on simple clinical and laboratorial tests, to be used in hospitalized patients with acute severe febrile disease in Northeastern Brazil. The definition reached an average sensitivity and specificity but presented with a high positive predictive value. This finding, allied to its simplicity and low cost, makes it useful for rapid bedside diagnosis and for assistance in therapeutic decisions, before a rapid and early sensitive laboratory test becomes available.

\section{CONFLICT OF INTEREST}

The authors declare that there is no conflict of interest.

\section{REFERENCES}

1. Terpstra WJ. International leptospirosis Society. Human Leptospirosis: Guidance for diagnosis, surveillance and control. Geneva: World Health Organization, 2003.

2. Mcbride AJA, Santos BL, Queiroz A, Santos AC, Hartskeerl RA, Reis MG, et al. Evaluation of four whole-cells leptospira-based serological tests for diagnosis of human leptospirosis. Clin Vaccine Immunol 2007; 14:1245-1248.

3. Rao P, Sethi S, Sud A, Banga SS, Sharma M. Screening of patients with acute febrile illness for leptospirosis using clinical criteria and sorology. Natl Med J India 2005; 18:244-246.

4. Bal AM, Kakrani AL, Bharadwaj RS, Kagal AS, Joshi AS, Arjunwadkar VP. Evaluation of clinical criteria for the diagnosis of leptospirosis. J Assoc Physicians India 2002; 50:394-396.

5. Shivakumar S, Shareek PS. Diagnosis of leptospirosis utilizing modified Faine's criteria (letter). J Assoc Physicians India 2004; 52:678-679.

6. Dassanayake DLB, Wimalaratna H, Agampodi SB, Liyanapathirana VC, Piyarathna TACL, Goonapienuwala BL. Evaluation of surveillance case definition in the diagnosis of leptospirosis, using the microscopic agglutination test: a validation study. BMC Infect Dis 2009; 9:48.

7. Jaeschke R, Guyatt GH, Sackett DL. User's guide to the medical literature. III. How to use an article about a diagnostic test. B. What are the results and will they help me in caring for my patients? JAMA 1994; 271:703-707.

8. Faine S. Guidelines for the control of leptospirosis. Geneva: World Health Organization; 1982.

9. Sackett DL, Haynes RB. Evidence base of clinical diagnosis: the architecture of diagnostic research. BMJ 2002; 324:539-541.

10. Flahault A, Cadilhac M, Thomas G. Sample size calculation should be performed for design accuracy in diagnostic test studies. J Clin Epidemiol 2005; 58:859-862.

11. Mcbride AJA, Pereira FA, Silva ED, Matos RB, Silva ED, Ferreira AGP, et al. Evaluation of the EIE-IgM Leptospirose assay for the serodiagnosis of leptospirosis. Acta Trop 2007; 102:206-211.

12. Dey S, Mohan M, Ramadass P, Nachimuthu K. Diagnosis of leptospirosis by recombinant antigen based single serum dilution ELISA. Indian J Med Res 2008; 128:172-177.

13. Mulla S, Chakraborty T, Patel M, Pandya HP, Dadhaniya V, Vaghela G. Diagnosis of leptospirosis and comparison of ELISA and MAT techniques. Indian J Pathol Microbiol 2006; 49:468-470.

14. Ministério da Saúde. Doenças infecciosas e parasitárias: guia de bolso. $6^{\text {th }} \mathrm{ed}$. rev. Brasília: Secretaria de Vigilância em Saúde. Departamento de Vigilância Epidemiológica; 2005.

15. Mathur M, De A, Turbadkar D. Leptospirosis outbreak in 2005: L.T.M.G. hospital experience. Indian J Med Microbiol 2009; 27:153-155.

16. Jaeschke R, Guyatt GH, Sackett DL. User's guide to the medical literature. III. How to use an article about a diagnostic test. A. Are the results of the study valid? JAMA 1994; 271:389-391.

17. Fonseca CA, Freitas VLT, Romero EC, Spinosa C, Sanches MCA, Silva MV, et al. Polymerase chain reaction in comparison with serological tests for early diagnosis of human leptospirosis. Trop Med Int Health 2006; 11:1699-1707. 